\title{
Past meets present
}

Received (in revised form): 16th May, 2008

\section{Peter Kaczmar}

is a timber coatings and treatments specialist and heads the research into timber flooring for TRADA Technology Ltd who provide services for the Timber Research and Development Association (TRADA). His work includes a f150,000 research project investigating stain blocking primers for wood joinery carried out through the Partners in Innovation programme. He has authored many technical guides on the topic of timber flooring. TRADA Technology Ltd are the UK's leading consultancy providing timber expertise and research to the timber and construction industry.

Correspondence: Peter Kaczmar, Flooring Consultant, Timber Research and Development Association (TRADA), Chiltern House, Stocking Lane, Hughenden Valley, High Wycombe, Bucks, HP14 4ND, UK; Tel: +0 1494 569600; Fax: +0 1494 565487; E-mail: pkaczmar@trada.co.uk

\section{Abstract}

This paper discusses the fine balance between past and present in restoration and remedial work in historic buildings, with particular regard to timber floor installation. The fact that timber is a natural material and subject to movement is discussed in terms of modern requirements for a more engineered machined finish. By use of a case study it is illustrated that high levels of relative humidity can cause severe deflection in such surfaces, which traditionally would have been accepted as a consequence of using timber and accommodated by a looser assembling regime that allows for expansion of the timber, and also robust fixing methods. The paper proposes anticipation of such movement and the use of wider expansion gaps, along with the use of moisture barriers and greater care in the sourcing of the timber used, to combat future problems of this kind. Journal of Building Appraisal (2008) 4, 33-36. doi:10.1057/jba.2008.16

\section{Keywords:}

moisture related movement, constructional synergy, moisture barrier

There is always an uneasy balance to be struck in the restoration of old or historic buildings. On the one hand, there is the need to ensure that the character of the building is not compromised, while on the other functional and cost-effective solutions must be found, without creating an unrealistic maintenance burden.

In the context of restoration and remedial maintenance in historic buildings there is, too, the perennial conundrum of the chronological mismatch of materials. The materials and indeed skills used in a given period may no longer exist today. Nowhere is this more evident than in the case of floors and flooring.

Installation practices and flooring materials have changed out of all recognition. Modern systems depend on a synergy with the 'fabric' of the building, a consideration that to a large extent was absent in days gone by. In the past, a floor installation may have been 'loosely' fixed using square-cut boards of different widths cut from a variety of species.

This meant that shrinkage between members was unpredictable. The tendency of the boards to distort was accepted as a normal consequence of using timber as a building material. This distortion was, at best, discouraged by using unsophisticated fixing methods - for example, hammering stout iron nails into boards to 'fix' them to underlying joists.

In contrast, today's flooring systems consist of accurately machined, interlocking boards or wood strips capable of providing a perfectly flat and unbroken floor surface 
without sacrificing its visual appeal as a natural material (Figure 1). In doing so, far greater demands have, however, been placed on constructional details to protect the floor from unacceptable levels of moisture-related movement.

I have seen striking examples of this constructional synergy and the potential for disastrous consequences on a number of consultancy visits carried out on listed buildings (Figure 2). Here, the relationship between the flooring and the constructional fabric of the building (ie the type of sub-floor construction and the provision of moisture-prevention measures on ground-floor installations) have only been put into the correct context after remedial works have been carried out.

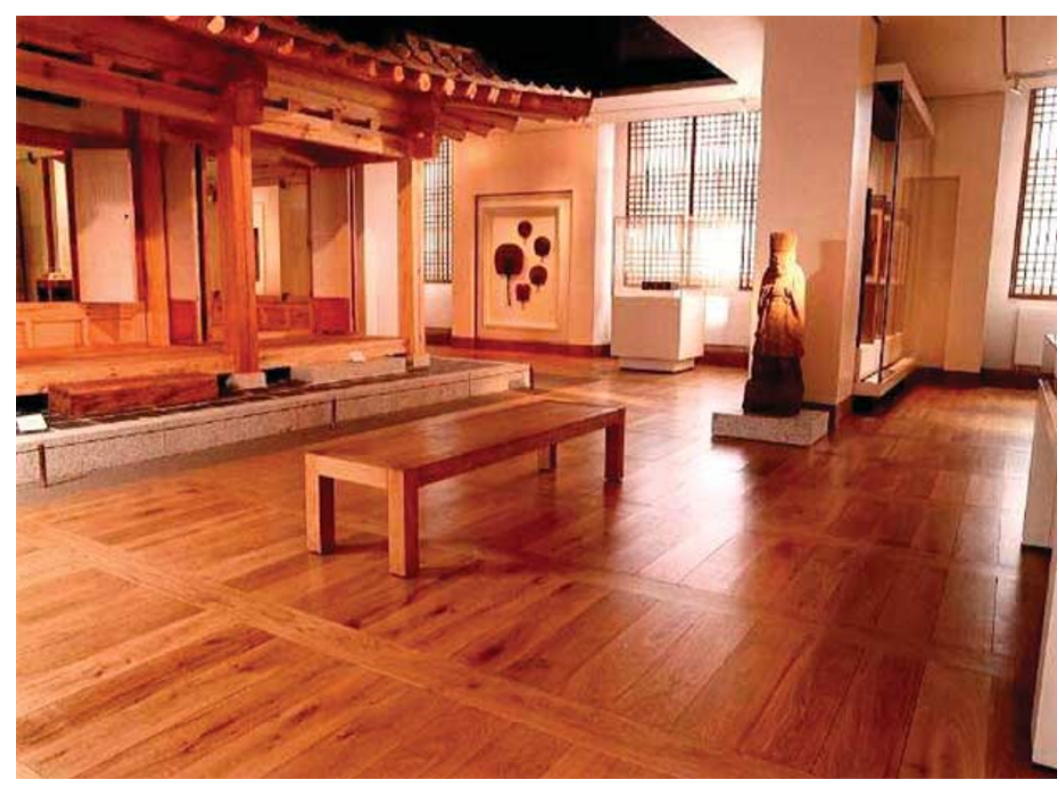

Figure I: European oak floor used in the Korean gallery of the British museum shows how modern wood flooring can be used successfully in a manner both sympathetic and complimentary to the architectural style of the building. Photo courtesy: British Museum Trustees/BonaKemi Ltd

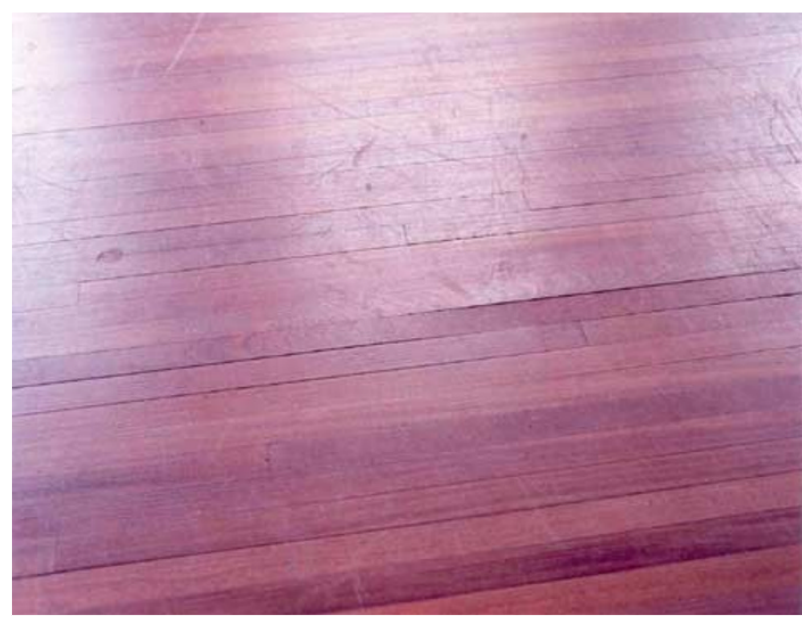

Figure 2: Floor cracking in service 
One case involved a recently renovated grade II-listed building, used as a theatre, which had a modern tongued and grooved softwood floor fitted onto ground floor joists suspended directly over an open soil sub-floor. There was no form of moisture protection in evidence, such as the provision of a vapour barrier.

The building had recently been fitted with a central heating system where some of the hot water pipes had been routed within the under floor void, while the original air bricks within the outer wall had been blocked by a peripheral inner block work structure which supported the ground floor joists. The air humidity within the void was measured at 97 per cent, with the consequence that the floor buckled and lifted by about 12 inches within a few weeks and continued to do so despite repeated attempts to remedy the problem.

This case shows how important it is to understand how the various constructional elements interplay and relate to each other. In this instance, the lack of a concrete sub-floor with an integral damp-proof course was the main reason for the failure. The siting of the peripheral block work joist mounting also showed a fundamental lack of understanding of the need for under floor ventilation. The case also illustrates that changes in lifestyle and habit (ie with the installation of central heating ducts) can be as much a contributory cause of failure as construction issues and can create new problems in the restoration of older buildings.

Cases like this clearly demonstrate the importance of a moisture barrier, such as a damp-proof course, to ensure the stability of the floor (Figure 3). If the installation of a ground slab is impossible on cost or other grounds, the simple expedient of protecting ground floors by a continuous thick-gauge polythene membrane, laid over the existing sub-floor, may serve as an adequate compromise against moisture-induced movement.

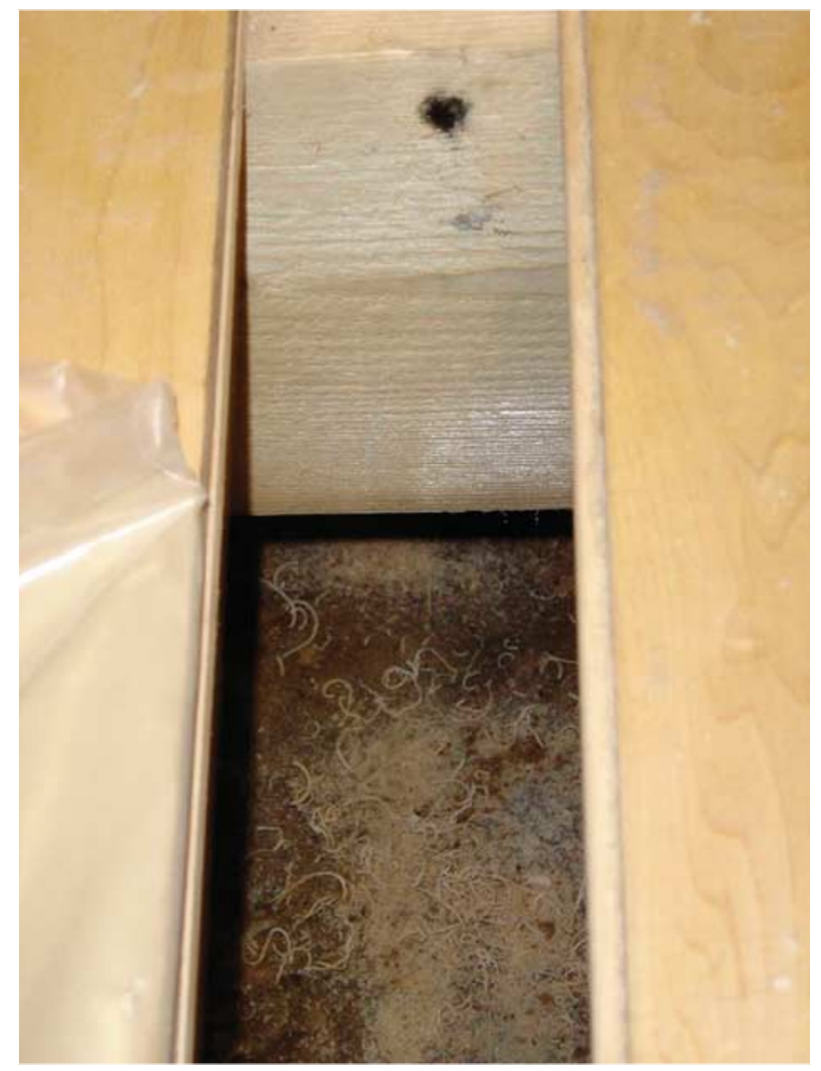

Figure 3: Flooring problems no membrane 
In cases where moisture movements are anticipated (including shrinkage) it is advisable to use small-movement flooring timbers such as Banga wanga or iroko in order to limit the level of anticipated distortion - although specifiers will generally be careful to obtain evidence that the timber has been legally sourced and only to use companies who can demonstrate full chain of custody back to the forest.

Floors should always be provided with peripheral expansion gaps to take-up in-service movement; and where large floor runs exceeding 12 metres measured at right angles to the lay of the boards occur, these should be broken with an expansion break to minimise the risk of lifting.

These are just some of the measures that can be used to stabilise timber components used in restoration works. None of these on their own, however, is a substitute for having a clear understanding of the existing construction details of the building and their effect and influence on contemporary building materials and systems. This is a process that often falls victim to modern day pressures of time and budget, illustrating, in more ways than one, the uneasy relationship between the old and the new. 